\title{
AN EXPERIMENTAL STUDY OF THE CONVECTIVE HEAT TRANSFER ENHANCEMENT: APPLICATION OF TURBULENCE PROMOTERS
}

\author{
P. S. B. Zdanski, \\ A. E. Bublitz, \\ and C. N. Correa \\ Universidade do Estado de Santa Catarina \\ Departamento de Engenharia Mecânica \\ Centro de Ciências Tecnológicas \\ Bairro Zona Industrial Norte \\ Joinville, Santa Catarina, Brasil \\ CEP 98219-710 \\ zdanski@joinville.udesc.br \\ cesarcnc@hotmail.com \\ aebublitz@gmail.com \\ Received: October 25, 2013 \\ Revised: November 20, 2013 \\ Accepted: December 30, 2013 \\ ABSTRACT \\ flows.

\section{NOMENCLATURE}

\begin{tabular}{|c|c|}
\hline $\begin{array}{l}\text { As } \\
\text { C } \\
\text { C }_{\text {promoter }}\end{array}$ & $\begin{array}{l}\text { heater surface area, } \mathrm{m}^{2} \\
\text { parameter for the Zhukauskas equation } \\
\text { experimental parameter for the turbulence } \\
\text { promoters, } \mathrm{W} /\left(\mathrm{m}^{2} . \mathrm{K}\right)\end{array}$ \\
\hline$\frac{C_{\text {La-p }}}{C_{\text {Dp }}}$ & relation between experimental parameters \\
\hline $\begin{array}{l}\mathrm{d} \\
\mathrm{D}\end{array}$ & $\begin{array}{l}\text { distance } / \mathrm{shape} \text { of the promoters, } \\
(\mathrm{W} . \mathrm{mm}) /\left(\mathrm{m}^{2} \cdot \mathrm{K}\right) \\
\text { heater diameter, } \mathrm{m} \\
\text { contraction height and width of the wind } \\
\text { tunnel, } \mathrm{cm} \\
\text { promoter characteristic length. } \mathrm{mm}\end{array}$ \\
\hline$h$ & $\begin{array}{l}\text { average convective heat transfer } \\
\text { coefficient, } \mathrm{W} /(\mathrm{m} . \mathrm{K})\end{array}$ \\
\hline $\begin{array}{l}\mathrm{k} \\
\mathrm{L} \\
\text { La-p } \\
1\end{array}$ & $\begin{array}{l}\text { fluid thermal conductivity, } \mathrm{W} /(\mathrm{m} . \mathrm{K}) \\
\text { contraction length of the wind tunnel, } \mathrm{cm} \\
\text { promoter distance from the heater, } \mathrm{mm} \\
\text { heater length, } \mathrm{m}\end{array}$ \\
\hline $\mathrm{Nu}_{\mathrm{d}}$ & Isselt number, $\bar{h} d / k$ \\
\hline $\operatorname{Pr}$ & randtl number, $v / \alpha$ \\
\hline $\begin{array}{l}\mathrm{Pr}_{\mathrm{s}} \\
\mathrm{P}_{\text {el }} \\
\mathrm{q}_{\mathrm{conv}} \\
\mathrm{q}_{\mathrm{rad}}\end{array}$ & $\begin{array}{l}\text { randtl number at surface temperature, } v / \alpha \\
\text { lectric power input, } \mathrm{W} \\
\text { onvective heat transfer rate, } \mathrm{W} \\
\text { nermal radiation heat transfer rate, } \mathrm{W}\end{array}$ \\
\hline
\end{tabular}

This work presents an experimental study addressing the effects of turbulence promoters on heat transfer rate at circular cylinder in external cross flow. Within this framework, the work focuses on assessing the effects of three kind of turbulence promoters (with circular, square and hexagonal cross sections) on convective heat transfer enhancement. The distance from turbulence promoters to the circular cylinder $(50,100$ and $150 \mathrm{~mm}$ upstream), as well as the free stream velocity inside the wind tunnel (Reynolds number) were the parameters investigated. The validation of the experimental methodology was performed by comparing the present results with empiric correlations available in the literature. The main results indicate that the convective heat transfer coefficient was enhanced when using turbulence promoters. The highest heat transfer enhancement obtained was around $25 \%$ correponding to the case of square turbulence promoter placed closely $(50 \mathrm{~mm})$ to the circular cylinder. Finally, it is worth mentioning that all the experimental results for the convective coefficient were condensed in a new empirical correlation with good accuracy.

Keywords: heat transfer enhancement, turbulence promoters, external
$\mathrm{Re}_{\mathrm{d}}$ Reynolds number based in the heater diameter, $U_{\infty} d / v$

$\mathrm{R}_{\mathrm{el}} \quad$ electric resistance of the heater, $\Omega$

$\bar{T} s \quad$ average temperature of the heater surface, $\mathrm{K}$

$T \infty$ free-stream temperature, $\mathrm{K}$

Uœ free-steam velocity in the wind tunnel, $\mathrm{m} / \mathrm{s}$

$\mathrm{V} \quad$ electric voltage, Volts

$\mathrm{xm}$ inflection point of the contraction, $\mathrm{Xm} / \mathrm{L}$

$\mathrm{x}$ distance measured from contraction entrance section, $\mathrm{cm}$

\section{Greek symbols}

$\varepsilon \quad$ surface thermal emissivity, Eq. (6)

$\sigma \quad$ Stefan-Boltzmann constant, $\mathrm{W} / \mathrm{m}^{2} . \mathrm{K}^{4}$

$\Phi$ diffuser diameter of the wind tunnel, $\mathrm{cm}$

$v$ fluid kinematic viscosity, $\mathrm{m}^{2} / \mathrm{s}$

$\phi \quad$ diffuser angle of the wind tunnel, ${ }^{\circ}$

\section{INTRODUCTION}

Heat transfer enhancement is instrumental on developing more efficient thermal systems, such as heat exchangers. Many techniques are commonly used to increase the heat transfer rate by improving thermal contact between the heat exchanger fluid and wall. The methods commonly used comprises: (i) manipulation of the surface, including its roughness, 
(ii) use of coiled tubes, fluid and surface vibration and (iii) vortex generators (Gajusingh et al., 2010; Chompookham et al., 2010). Vortex generators are solid objects (turbulence promoters) that disturb the flow causing flow separation leading to convection heat transfer enhancement. Different vortex generators have been proposed in the literature, being the most common the cubical and delta winglets (Gajusingh et al., 2010).

In the recent technical literature, the number of works assessing methods for convection heat transfer enhancement due to turbulence promoters is quickly growing. Focusing only on experimental works (with interesting practical applications) that make use of vortex generators, one finds: (i) Gunes et al. (2010) analysed the effects of turbulence promoters in a channel flow; The main findings indicate that a triangular promoter produces a maximum increment of around $35 \%$ on the local convective heat transfer rate; (ii) Ali (2009) evaluated the effect of a guide fence on convection heat transfer over a square heat source; Increments up to $20 \%$ on the mean convective heat transfer coefficient was reached; (iii) Chompookhan et al. (2010) studied the effects of wedge ribs and winglet type vortex generators on convection heat transfer rate and friction loss behaviour in a channel; The main results indicate increments around $20 \%$ on the Nusselt number when the wedge rib promoter was used; (iv) Promvonge et al. (2012) presented an experimental study on turbulent heat transfer characteristics in a square duct fitted diagonally with angle finned-tape promoters; The experiments indicate that smaller fin pitch spacing provides the highest heat transfer rates.

The main focus of the present work was to study experimentally the effects of three kinds of turbulence promoters on convective heat transfer rate in circular cylinder. The maximum convective heat transfer increment obtained was around $25 \%$ correponding to the case of a square turbulence promoter placed closely $(50 \mathrm{~mm})$ to the circular cylinder. Most importantly, it was found that all the experimental results collapse in a new empirical correlation with practical engineering applications.

\section{EXPERIMENTAL METHODOLOGY}

The experimental setup used in the present work is showed in Figs. 1 and 2. The cylindrical heater is positioned inside the test section of the wind tunnel on the Teflon support, being the turbulence promoters placed upstream (see Fig. 1). An open circuit wind tunnel of the suction type (range of velocities 5.5$9.5 \mathrm{~m} / \mathrm{s}$ ) was used (the main dimensions are illustrated in Fig. 2): $\mathrm{xm}=0.24, \mathrm{~L}=70 \mathrm{~cm}, \mathrm{~L} 1=60 \mathrm{~cm}, \mathrm{~L} 2=$ $70 \mathrm{~cm}, \phi=12^{\circ}, \Phi=50 \mathrm{~cm}, \mathrm{D} 1=60 \mathrm{~cm}$ and $\mathrm{D} 2=$ $25 \mathrm{~cm}$. The contraction ratio of the tunnel is $1: 6$ with a test section of $25 \mathrm{~cm} \times 25 \mathrm{~cm}$. The contraction of the tunnel was devised according to the following equations (Mattos et al., 2003):

$$
\frac{D(x)-D_{2}}{D_{1}-D_{2}}=1-\frac{1}{x m^{2}}\left(\frac{x}{L}\right)^{3}
$$

para $x / L \leq x m, \mathrm{e}$

$$
\frac{D(x)-D_{2}}{D_{1}-D_{2}}=1-\frac{1}{(1-x m)^{2}}\left(1-\frac{x}{L}\right)^{3}
$$

$\operatorname{para} x / L \geq x m$

The objective of the experimental work was to evaluate the convective heat transfer coefficient, and as a consequence the Nusselt number. Therefore, according to the Newton's law of cooling one finds (Incropera et al., 2006)

$$
\bar{h}=\frac{q_{\text {conv }}}{A s(\bar{T} s-T \infty)}, \quad N u_{d}=\frac{\bar{h} d}{k} \text {, }
$$

being

$$
q_{\text {conv }}=P_{e l}-q_{\text {rad }}
$$

The input electric power of the heater is measured indirectly, i.e,

$$
P_{e l}=\frac{(V)^{2}}{R_{e l}} \cos (\varphi)
$$

where the power factor, $\cos (\varphi)=0.98($ Ali, 2010). Otherwise, the radiation losses are estimated by

$$
q_{\text {rad }}=\varepsilon \sigma A s\left(\bar{T} s^{4}-T \infty^{4}\right)
$$

where $\varepsilon$ is the thermal surface emissivity and $\sigma$ is the Stephan-Boltzmann constant. It is worth mentioning that in the range of velocities tested the average radiation losses was around $10 \%$ of the input electric power. The average surface temperature (Ts) of the cylindrical heater was obtained with three k-type thermocouples. Otherwise, the free-stream temperature $(\mathrm{T} \infty)$ and velocity $(\mathrm{U} \infty)$ were measured by a thermo anemometer positioned inside the test section of the wind tunnel. Finally, the surface heat transfer area of the cylindrical heater $(\mathrm{As}=\pi \mathrm{dl})$ was indirectly measured by an analog caliper ( $\mathrm{d}$ and $1-$ diameter and length). The overall uncertainty was obtained applying the Klien and McClintok methodology (Doebelin, 1990; Mahalakshmi, 2007), being estimated an average value of around $\pm 4 \%$ for 
the convective heat transfer coefficient (with odds 95 to 1$)$.

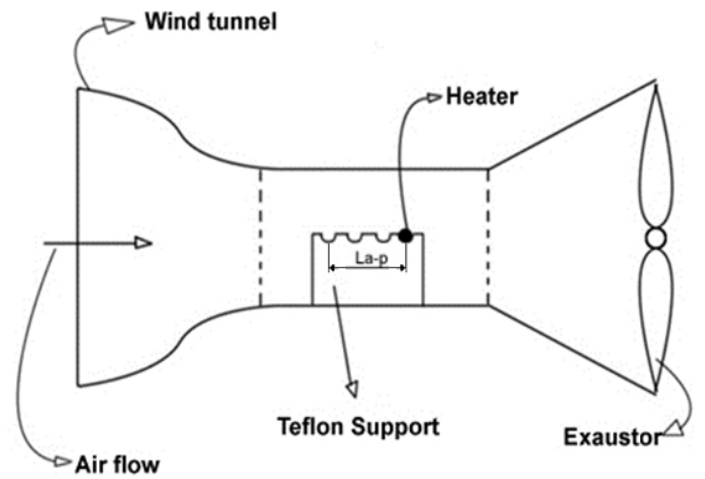

Figure 1. Arrangement of the turbulence promoters in the wind tunnel.

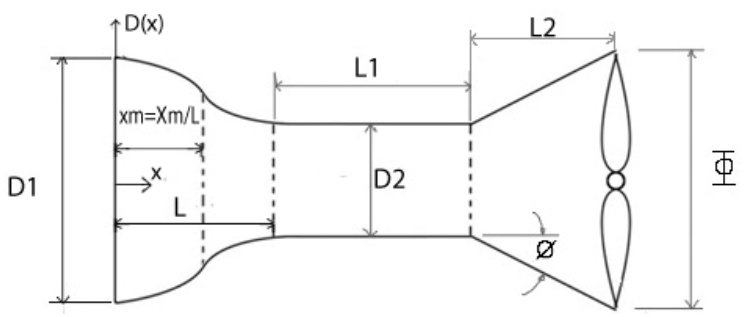

Figure 2. Illustration of the wind tunnel with the main dimensions.

\section{RESULTS AND DISCUSSION}

The results obtained in this study are divided in two parts: (i) experimental validation, and (ii) analysis of the effects of turbulence promoters on average heat transfer coefficient.

Firstly, at Fig. 3 the present experimental data are confronted with the classical Zhukauskas empirical correlation for the external cross flow in a circular cylinder (without turbulence promoters). The Zhukauskas correlation is given by

$$
\frac{\bar{h} d}{k}=N u_{d}=C \operatorname{Re}_{d} m \operatorname{Pr}^{n}\left(\frac{\operatorname{Pr}}{\operatorname{Pr}_{\mathrm{s}}}\right)^{0.25}
$$

where $\mathrm{C}, \mathrm{m}$ and $\mathrm{n}$ are constants defined according to the Reynolds number range (Incropera et al., 2006). In the preceding expression, $\mathrm{k}$ is the fluid thermal conductivity and Pr is the fluid Prandtl number (being the subscript $\mathrm{s}$ related to surface temperature condition). The validation procedure (see Fig. 3) shows a good agreement between the present work and the literature data (maximum error around $7 \%$ ). It is worth to mention that Zhukauskas empirical correlation has a precision around 10\% (Incropera et al., 2006).

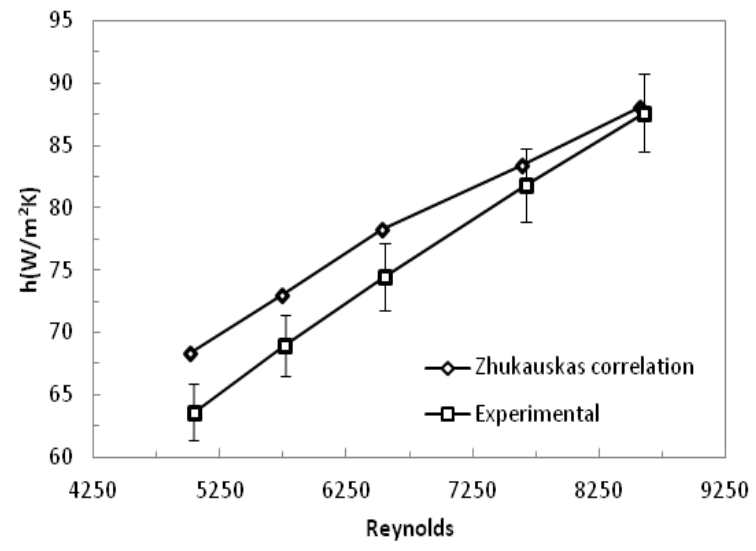

Figure 3. Experimental data (with error bars) versus empirical correlation for average heat transfer coefficient.

The main goal of the present work is to assess the influences of the turbulence promoters on convective heat transfer rate at circular cylinder in cross flow. Three type of promoters were investigated, i.e: square, circular and hexagonal cross sections (as can be seen in table 1). For each promoter type, three distinct dimensions were tested. It is important to mention that the promoters dimensions were selected from material that was commercially available.

Table 1. Promoters type with their dimensions.

\begin{tabular}{|c|c|c|c|}
\hline \multirow{2}{*}{ Promoter } & $\mathrm{D}_{\mathrm{p}} \mp$ & $\mathrm{D}_{\mathrm{p}}\lceil$ & $\mathrm{D}_{\mathrm{p}}$ \\
\hline \multirow{2}{*}{$\begin{array}{c}\text { Size } \\
(\mathrm{mm})\end{array}$} & 9.5 & 9.5 & 9.5 \\
\cline { 2 - 4 } & 12.5 & 12.5 & 11.0 \\
\hline
\end{tabular}

Figure 4 shows the results for the promoters with dimension, $\mathrm{Dp}=9.5 \mathrm{~mm}$, and positioned at a distance, La-p $=150 \mathrm{~mm}$, upstream of the cylindrical heater. The results clearly indicate that the promoter with square cross section presents the best performance in convection heat transfer enhancement for the Reynolds number range tested (the maximum increment for the convective coefficient was around $25 \%$ for the Reynolds number 7000 ). It is important to mention that the same behaviour was observed for others promoter dimensions (Dp) in each position (La-p) tested (the best thermal behaviour was always obtained with square promoters). Probably, the physical justification for this behaviour is that the square promoter disturbs the flow producing a higher turbulence level due to its sharp corners (the hexagonal and circular promoters are less effective due to theirs more rounded shape). 


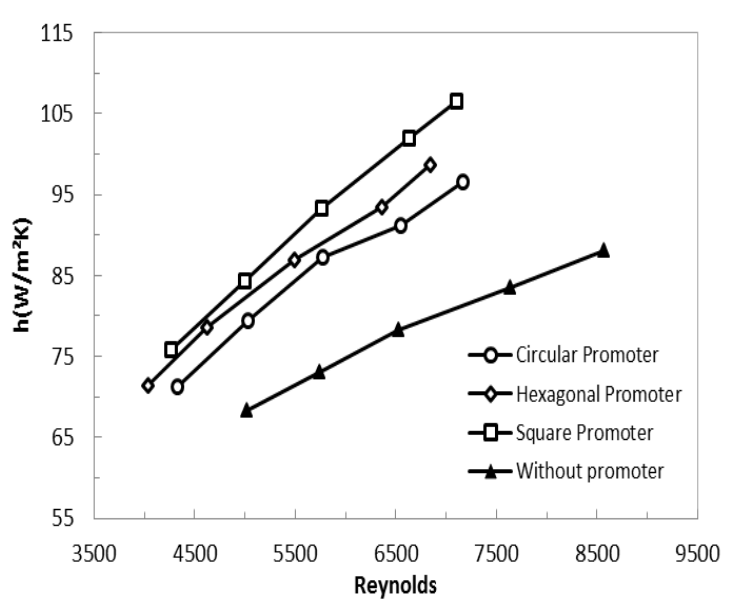

Figure 4. Convective heat transfer coefficient for promoters with distinct cross sections.

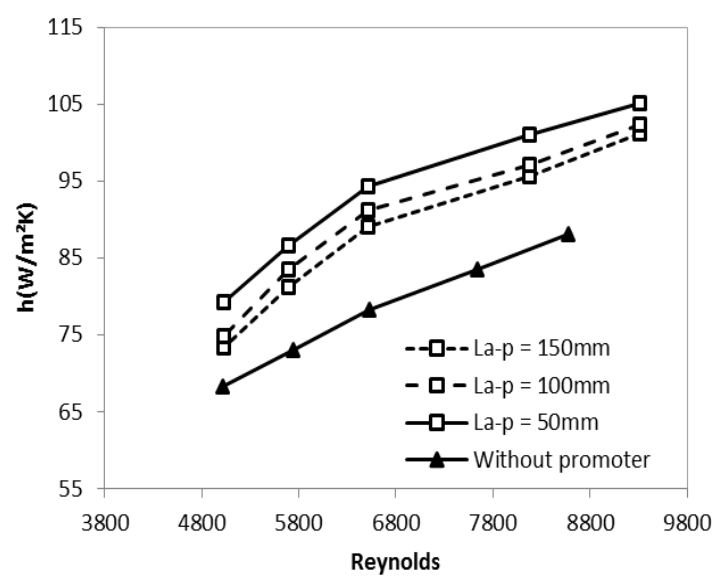

Figure 5. Convective heat transfer coefficient for a square promoter at different positions upstream of the heater.

The convective heat transfer coefficient for the circular heater with the square promoter, $\mathrm{Dp}=6.5 \mathrm{~mm}$, as function of the parameter La-p is presented in Fig. (5). The results clearly indicate that the best thermal performance is obtained when the promoter is placed closely to the heater (La-p=50mm). Furthermore, it is important to mention that the same behaviour was observed for circular and hexagonal turbulence promoters tested in the present work.

Finally, all the results obtained in the present study may be collapsed in a new correlation for the average convective heat transfer coefficient, i.e,

$$
\bar{h}=C_{\text {promoter }} C \operatorname{Re}_{d}{ }^{m} \operatorname{Pr} n\left(\frac{\operatorname{Pr}}{\operatorname{Pr}_{\mathrm{S}}}\right)^{0.25}
$$

where the new parameter that takes into account the effects of turbulence promoters is given by

$$
C_{\text {promoter }}=\left(\frac{C_{L a-p}}{C_{D p}}\right)\left(\frac{L_{a-p}}{D_{p}^{2}}\right) .
$$

In the preceding expression (Eq. (9)), La-p and Dp are given in millimetres and $\mathrm{C}_{\text {La-p }}$ e $\mathrm{C}_{\mathrm{Dp}}$ are evaluated according to the data of Figs. $6-9$. Besides, the related figures present fit curves for the parameters with good accuracy (coefficient of determination $\mathrm{R}^{2}$ $=0.99$ ). Furthermore, the fluid thermal properties on using the Eqs. (8) e (9) must be evaluated at the freestream temperature $(T \infty)$, except the $\operatorname{Pr}_{\mathrm{s}}$ that is estimated at the surface temperature. It is quite remarkable that the preceding expression gives the average convective coefficient for all promoters type and size (see table 1), and for all the Reynolds number range tested with a maximum error of around $6.5 \%$ (the error being defined as the difference between the experimental value and the one obtained with the new correlation).

Finally, it is important to emphasize that the Eq. (8) performs a correction to the classical Zhukauskas correlation for circular cylinders (see Eq. (7)), including the effects of turbulence promoters. To the authors knowledge, this aspect contributes to the technical heat transfer literature, especially to practical industrial applications where convection heat transfer rates from cylinders in external cross flow needs to be estimated.

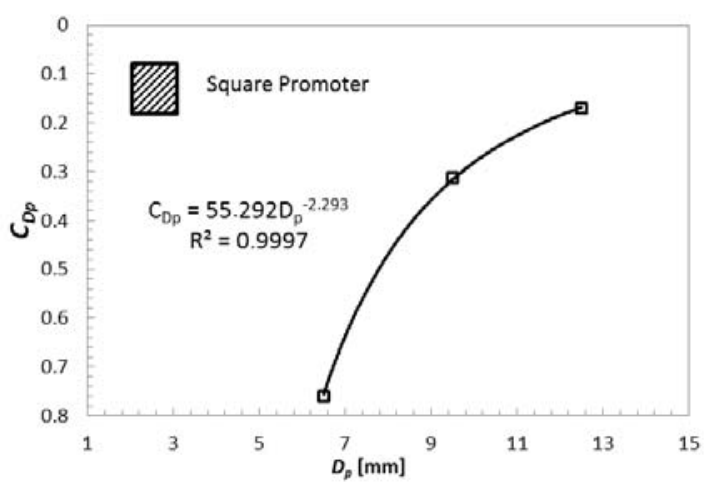

Figure 6. Coefficient $\mathrm{C}_{\mathrm{Dp}}$ for the square promoter.

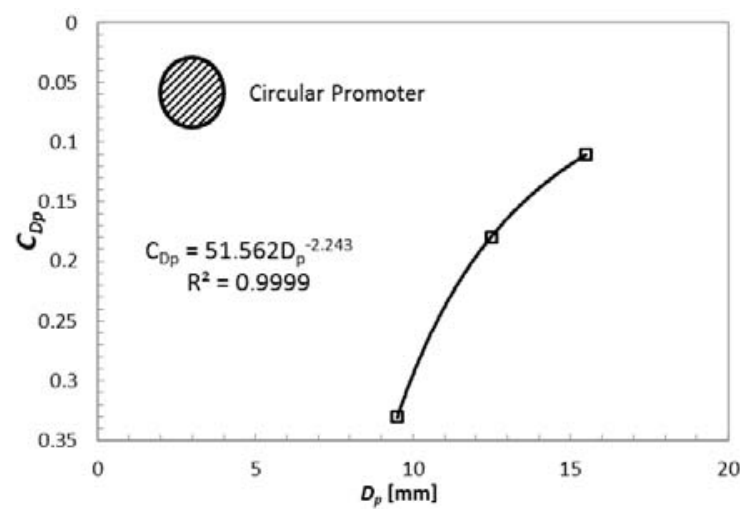

Figure 7. Coefficient $\mathrm{C}_{\mathrm{Dp}}$ for the circular promoter. 


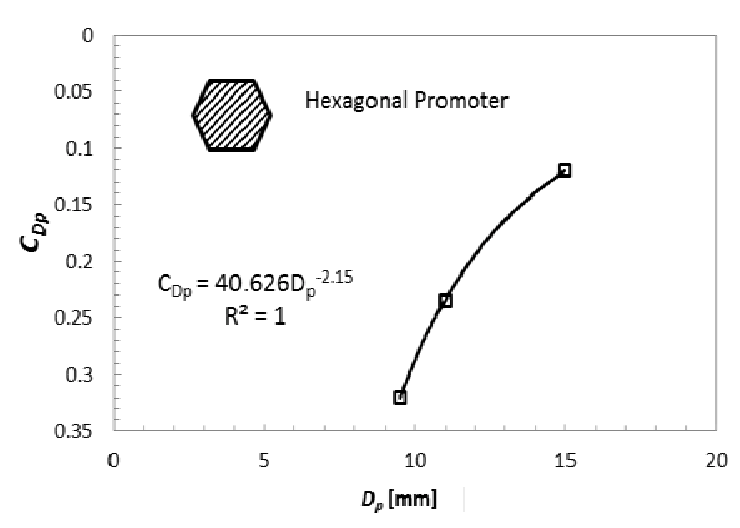

Figure 8. Coefficient $\mathrm{C}_{\mathrm{Dp}}$ for the hexagonal promoter.

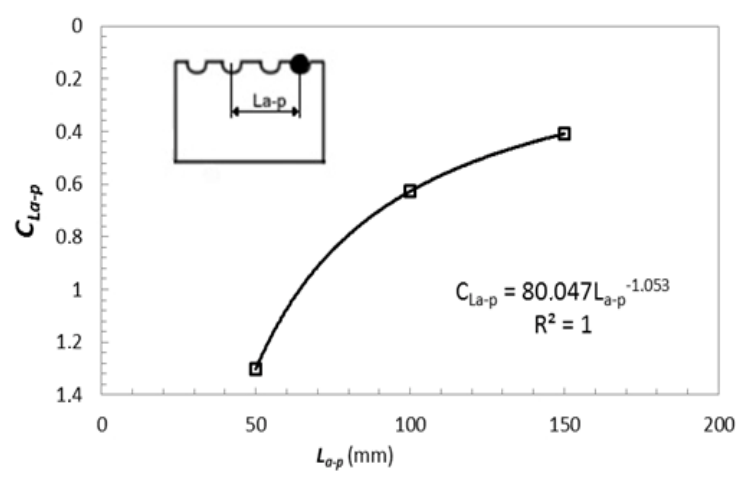

Figure 9. Coefficient $\mathrm{C}_{\mathrm{La}-\mathrm{p}}$ for the square, circular and hexagonal promoters.

\section{CONCLUSIONS}

In the present work an experimental study was conducted to investigate the effects of turbulence promoters on heat transfer rates in circular cylinders subjected to cross flow conditions. The experimental methodology employed was validated comparing the present results with literature data. The main conclusions are as follows: (i) better thermal performance was achieved for the square promoter placed closely to the cylindrical heater, and (ii) most importantly, all the experimental results obtained were condensed in a new practical empirical correlation for convective heat transfer coefficient in the presence of turbulence promoters (with good accuracy - the maximum error was about $6.5 \%$ ).

\section{ACKNOWLEDGEMENTS}

The first author acknowledges the financial support and scholarship provided by the by $\mathrm{CNPq}$ (National Council for Scientific and Technological Development) under grants 470581/2012-3 and 301711/2012-7.

\section{REFERENCES}

Ali, R. K., 2009, Augmentation of Heat
Transfer from Heat Source Placed Downstream a Guide Fence: an Experimental Study, Experimental Thermal and Fluid Science, Vol. 33, pp. 728-734.

Chompookham, T., Thiangpong, C., Kwankaomeng, S., and Promvonge, P., 2010, Heat Transfer Augmentation in a Wedge-Ribbed Channel Using Winglet Vortex Generators, International Communications in Heat and Mass Transfer, Vol. 37, pp. 163-169.

Doebelin, E. O., 1990, Measurement Systems Application and Design, 4th Edition, McGraw-Hill.

Gajusingh, S. T., Shaikh, N., and Siddiqui, K., 2010, Influence of a Rectangular Baffle on the Downstream Flow Structure, Experimental Thermal and Fluid Science, Vol. 34, pp. 590-602.

Gunes, S., Ozceyhan, V., and Buyukalaca, O., 2010, Heat Transfer Enhancement in a Tube with Equilateral Triangle Cross Sectioned Coiled Wire Inserts, Experimental Thermal and Fluid Science, Vol. 34, pp. 684-691.

Incropera, F. P., Dewitt, D. P., Bergman, T. L., and Lavine, A. S., 2007, Fundamentals of Heat and Mass Transfer, 6th Edition, John Wiley \& Sons.

Mattos, B., Fico Jr., N. G. C. R., and Girardi, R. M., 2003, Design of ITA's Research Wind Tunnel Contraction Using CFD Tools, Proceeding of the 21st Applied Aerodynamics Conferece, Orlando, EUA, pp. 1-11.

Mahalakshmi, N. V., Krithiga, G., Sandhya, S., Vikraman, J., and Ganesen, V., 2007, Experimental Investigations of Flow Through Conical Diffusers With and Without Wake Type Velocity Distortions at Inlet, Experimental Thermal and Fluid Science, Vol. 32, pp. 133-157.

Promvonge, P., Skullong, S., Kwankaomeng, S., and Thiangpong, C., 2012, Heat transfer in Square Duct Fitted Diagonally with Angle-Finned Tape Part 1: Experimental Study, International Communications in Heat and Mass Transfer, Vol. 39, pp. 617-624. 